\title{
NOS BASTIDORES DA PALAVRA
}

\author{
Luciano Fussieger
}

ABSTRACT: The present article is the result of a compilation of ideas which were extendedly developed in the mandatory final paper for UFRGS to obtain the qualification of undergraduate teacher in languages and literature. The subject are the narratives (tales) that come from the Brazilian oral tradition and which are crystalised by writing. Such narratives are intended to be affiliated to the family of dramatic texts (through comparisons with some theatrical expressions as the Commedia dell'Arte), taking them out of the field of comparison with narrative texts, fact which has always reinforced the idea of lower aesthetic value of this kind of literary manifestation. Through this new theoretical perspective we try to demonstrate how the tales that come from the oral tradition are embedded with some theatrical characteristics, which arouse only in the contexts in which the tales are fully successful, i. e. performatic contexts. In this sense, we defend the idea that such tales, when written, are formally close to theatrical texts.

PALAVRAS-CHAVE: Contos orais/tradicionais, teatro, Commédia Dell'arte, performance

Imaginemos uma experiência teatral. Muito bem sentados em suas poltronas, o público espera o início de uma peça. À frente, no palco, vê-se a cortina cerrada e sobre esta uma tela. O sinal marca o tempo para o início. Pessoas ainda buscam poltronas, enquanto outras falam em tom baixo. Ouve-se o último sinal. A expectativa e o silêncio tomam conta do teatro. Súbito, aparecem palavras escritas na tela. Dão-se as notícias de que a peça está se iniciando e de que o público nada verá e nada ouvirá. Os atores estão por de trás da cortina e lá executarão a peça. Ao público basta acompanhar tudo pelas legendas que aparecerão na tela.

Seria essa uma experiência teatral? Estaria o público frente a uma dramatização ou frente a uma experiência de leitura coletiva? Mesmo sabendo que a peça está sendo executada e de que o texto está sendo dramatizado é essa uma experiência completa para o público? Tem ele acesso à totalidade de significações envolvidas na peça? Se pensarmos que o público tem somente acesso ao texto na forma escrita e que ele (o público) só imagina o gesto, a voz, a expressão dos atores (pois foi informado de que isso está acontecendo), podemos afirmar que esse público não consegue abraçar a totalidade da peça. Em verdade, esse público está alienado da performance teatral, característica fundamental que diferencia a simples leitura de um texto da sua dramatização.

Pensando o objeto de reflexão deste ensaio, os contos de origem tradicional/oral, há uma relação análoga entre o público de nossa peça "vanguardista" e o público leitor desses contos. Ambos estão distanciados do caráter performático que agrega sentidos múltiplos e variados aos textos. No caso dos contos coletados na oralidade e posteriormente cristalizados na forma escrita, temos que esse processo de desconhecimento por parte do público em relação à totalidade complexa da expressão literária que os contos representam difunde a falsa idéia de que estes contos possuem um menor valor estético/literário quando comparados aos contos provindos da tradição escrita - idéia esta vigente no senso comum da crítica literária.

De fato, comparando-se os contos tradicionais/orais ${ }^{1}$ com o que chamarei de contos eruditos/canônicos, em suas formas estritamente textuais, os primeiros passarão a idéia de simplicidade e outras idéias afins. Fazendo uma análise somente no âmbito do textual e comparando formas e elementos

\footnotetext{
Graduando em Letras pela Universidade Federal do Rio Grande do Sul.

Tenha-se em mente que esses contos estão aqui representados pelas coletas de Sílvio Romero, Câmara Cascudo e Lindolfo Gomes, somando um total de 300 narrativas.
} 
narrativos, vemos de onde provêm tais idéias. Realmente, os contos tradicionais/orais trabalham com um tempo/espaço restrito, ao que podemos chamar de mítico. O foco narrativo é constante. E as personagens são tipos (a madrasta, o príncipe, o filho mais novo), de pouca ou nenhuma profundidade psicológica. Já os contos eruditos/canônicos trabalham dentro de um universo maior de tempos (cronológico, psicológico, mítico, etc) e espaços (mítico, real/físico, etc). Usam uma série de focos narrativos e formas distintas de comportamento do narrador. Quanto às personagens, podem por vezes usar personagens tipos, mas há uma preferência pela construção de personagens de ações complexas que oscilam entre eixos dicotômicos (bem/mal, sagrado/profano, etc), possuidores de uma densidade psicológica que os coloca num processo de individualização. Restrito a esta visão, um leitor contemporâneo, acostumado a decifrar charadas narrativas complexas, pode realmente sentir um desdém frente à simplicidade formal dos textos escritos que procuram cristalizar narrativas provindas da oralidade. Porém, um olhar mais atento - olhar sem pré-conceitos - sobre esses textos pode nos mostrar traços de sua complexidade exterior, para além da escrita: os gestos, a voz, o corpo e todos os elementos que estão por trás da cortina cerrada e que são utilizados pelos atores dessa "peça teatral". E se mantivermos a analogia proposta, também essas narrativas, a exemplo dos textos dramáticos, perdem significação quando vistas somente através da ótica restrita do textual, do escrito. Com efeito, parece que as narrativas orais pertencem muito mais à família dos textos dramáticos do que à dos textos narrativos. Essa é a idéia central deste ensaio e é o norte das análises propostas.

Ainda dentro da questão formal do texto, vemos duas características marcantes nos contos tradicionais/orais que os diferenciam dos contos eruditos/canônicos. Há uma intensidade maior de ações e situações que são narradas, em detrimento de uma maior descrição de cenas, personagens e espaços. Essa primazia pela ação constrói uma narrativa ágil, de curta duração, onde as tensões entre personagens e situações produzem movimentações consecutivas das personagens, conduzindo o enredo rapidamente para um desfecho, muitas vezes óbvio desde as primeiras linhas. Essa característica intrínseca aos contos tradicionais/orais me faz pensar em sua aproximação com os textos dramáticos, pois estes são fundamentalmente caracterizados por ocorrerem "num meio repleto de conflitos e oposições", ou seja, há uma ação dramática explícita que "dá origem a ações e reações" por parte das personagens (HEGEL, 1964, p. 375). Sendo esse o mecanismo que engendra o texto dramático, vejamos um exemplo de como isso se dá numa narrativa oral:

Era uma vez um reino em que havia uma princesa que gastava sete pares de sapatos por noite. Ninguém podia explicar esse mistério. Vai então Joãozinho, um rapazote que andava correndo mundo e que saíra de casa com a benção do pai, tinha chegado a essa terra e ouviu dêsse misterioso caso. O rei daria a mão da princesa em casamento a quem descobrisse tudo como era. Mas quem o tentasse e não descobrisse daria a cabeça a degolar. Muitos já tinham tentado e recebido o grande castigo. Mas Joãozinho que era moço de muita coragem e confiança apresentou-se em palácio. (GOMES, 1965, p. 157).

Já na primeira frase, temos um universo de informações que passam despercebidas, pois camufladas numa aparente simplicidade. "Era uma vez" é uma clara expressão formular, fixa, muito corriqueira no início de narrativas orais, que evoca um tempo mítico, indefinido, e com isso coloca o narrador fora do universo da narrativa, ou seja, o foco narrativo é exterior à história narrada. Essa relação é importante, pois, sendo o narrador de tradição oral um contador de histórias, cuja presença física se dá no momento do ato de contar, não pode ele estar, nem mesmo evocar para seu público, um tempo mítico. Ele encarna o papel de mediador entre um tempo distante e a realidade presente da comunidade ouvinte. "Era uma vez um reino" é a continuação da relação de distância entre os ouvintes presentes, seu tempo, e agora seu espaço, pois "um reino" remete a um espaço qualquer, fisicamente possível, porém da ordem do mítico, dado que impossível de ser identificado. "Era uma vez um reino em que havia uma princesa" completa a seqüência de informações. Temos na ordem tempo, espaço e personagem, sendo que esse último elemento se afigura como o elemento central, ou seja, a personagem principal. Olhando com mais atenção, vemos com estranhamento uma série de silêncios, que demonstram a primazia da narração de ações em detrimento das descrições. Pensemos: "um reino", mas como é esse reino? As pessoas? O rei? O castelo? A corte? O lugar ao redor? "Uma princesa", mas como é ela? Feia? Bonita? Qual a cor do seu cabelo? E seu humor? Muitas dessas perguntas podem ter respostas óbvias para quem as leu há pouco. Sim, é "óbvio" que o reino é belo, senão o mais belo do mundo; com "certeza", a princesa é bela, talvez a mais bela dentre todas princesas; e assim por diante. Essa "obviedade", ou melhor, essas informações que temos a respeito da personagem e do espaço são o que chamarei de topos, segundo concepção de dois estudiosos britânicos, Kellogg e Scholes:

Um topos, ocorra numa narrativa oral ou escrita, é uma imagem tradicional. Ele não é identificável, nem mesmo analisável à base nem das fórmulas nem das palavras dispostas de maneira singular que um poeta possa usar para construí-lo, mas sim à base da imagem à qual as 
palavras se referem. Em suma, podemos dizer que, quando um topos se refere ao mundo externo, significa um motivo; quando se refere ao mundo de idéias e conceitos desincorporados, significa um tema. (SCHOLLES; KELLOGG, 1977, p. 17-18)

Sendo assim, sabemos o porquê da nossa capacidade de preencher as aparentes lacunas do texto, no caso em questão, as caracterizações do reino e da princesa. Somos levados a isso porque estamos mergulhados numa tradição que vincula motivos e temas. Mesmo que nos encontremos longe de uma cultura de oralidade primária ${ }^{2}$, somos descendentes de uma tradição oral que se mantém entretecida com diversos veículos de informação, não só os escritos, mas também as diversas mídias contemporâneas ${ }^{3}$.

Voltemos ao trecho do conto tradicional/oral. Tomemos ainda a primeira frase: "Era uma vez um reino em que havia uma princesa que gastava sete pares de sapato por noite". Temos aí exposto, de imediato, o conflito central do conto, fato que nos remete à idéia acima discutida sobre a natureza dos textos dramáticos. Este conflito, que irá desencadear as sucessivas ações das personagens, é apresentado diretamente, sem descrições de nenhuma natureza. A partir dessa primeira frase, das informações de tempo, espaço, personagens e do conflito, irão desencadear-se todas as ações, reações e conflitos constituintes da totalidade do conto. A maioria desses elementos está expressa nas primeiras linhas do texto. Por exemplo, temos a personagem principal e sua ação conflituosa (quebra da normalidade), "gastar sete pares de sapato por noite"; o conflito, "ninguém podia explicar esse mistério"; a segunda personagem, "Joãozinho", caracterizada por ser moço e ter muita coragem e confiança, elementos opositores importantes. Na seqüência, deparamo-nos com outro conflito: "O rei daria a mão da moça a quem descobrisse tudo como era. Mas quem o tentasse e não descobrisse daria a cabeça a degolar.". Daí nasce a tensão que será motor das ações narradas, as quais buscam a restauração de uma ordem "normal", quebrada pelos conflitos. Ou seja, temos pares de oposições: Princesa X Joãozinho (moço); recompensa (casar com a princesa) $\mathrm{X}$ castigo (ter a cabeça degolada); o fracasso de muitos (que foram degolados) $\mathrm{X}$ a coragem de Joãozinho; e o mistério (nunca resolvido) X a confiança que Joãozinho tem em si; que nos levam a um ápice de tensão dramática entre as personagens, que será resolvida no decorrer das ações. Lembrando as características mencionadas dos textos dramáticos (são fundamentalmente caracterizados por ocorrerem num meio repleto de conflitos e oposições), podemos vislumbrar a dramaticidade contida nessa narrativa oral, cuja dramaticidade está marcada textualmente, como demonstramos acima.

Outra aproximação entre os contos tradicionais/orais e textos dramáticos nasce quando pensamos expressões teatrais distintas. É verdadeiramente frutífera a comparação, por exemplo, com a Commedia dell'Arte. Expressão teatral nascida na Itália renascentista e de caráter eminentemente popular, que utilizava o cômico como elemento característico, a Commedia dell'Arte conviveu durante quase três séculos (quando perdeu espaço devido ao esgotamento de sua estética) com o teatro erudito de linha trágica. As características fundamentais desse tipo de teatro aproximam-se muito dos elementos que vislumbramos nas narrativas orais. Organizada em torno da figura do ator, ou seja, de tendência puramente performática, a Commedia dell'Arte não se utilizava de textos dramáticos. Ao invés disso, os atores usavam pequenos esquemas de entradas e saídas do palco, acrescidos de uma conferência prévia à apresentação, a partir da qual decidiam como seria montado o espetáculo. Dario Fo, estudioso dessa expressão teatral, nos fala sobre o tema:

Os cômicos possuíam uma bagagem incalculável de situações, diálogos, gags, lengalengas, ladainhas, todas arquivadas na memória, as quais utilizavam no momento certo, com grande sentido de timing, dando a impressão de estar improvisando a cada instante. Era uma bagagem construída e assimilada com a prática de infinitas réplicas, de diferentes espetáculos, situações acontecidas também como o contato com o público [...]. (FO, 1998, p. 17)

Podemos notar por esse trecho que os atores da Commedia dell'Arte se utilizavam, assim como os contos tradicionais/orais, de topos para montarem o seu espetáculo. Eles eram conhecedores de uma gama infinita de histórias, cantos, poemas, vinculados pela sua tradição, os quais eram maciçamente utilizados e remodelados a cada apresentação, de forma a dar a impressão ao público de que estavam improvisando suas histórias. Na verdade, a apresentação partia de um motivo ou de um tema conhecido. Por exemplo, um círculo vicioso de paixões, no qual cada personagem se apaixona perdidamente por outra personagem, sendo que nenhuma das paixões é recíproca nem correspondida. A essa fórmula eram acrescidos, na hora da apresentação, inúmeros elementos conhecidos por parte do ator.

Ao falar das personagens, chegamos a outro ponto comum entre a Commedia dell'Arte e as narrativas orais. Já nos referimos à constituição das personagens nos contos tradicionais/orais como sendo de tipos. A mesma constituição vislumbramos na Commedia dell'Arte, também nela há a presença das

\footnotetext{
2 Concepção criada por Walter Ong, referindo-se à uma cultura que não tenha tido acesso a nenhuma forma de escrita.

3 Pensemos, por exemplo, quanto os desenhos de Walt Disney e outros programas infantis alimentam-se dos temas e motivos historicamente vinculados aos contos, lendas, romances, poemas, de diferentes tradições orais.
} 
personagens tipo, representativas de um horizonte de expectativas a elas atrelado pela tradição. Encontramos nas máscaras ${ }^{4}$, que recobrem os rostos dos atores, diversos padrões de comportamento dos tipos representados. Assim temos, segundo Andrade (2006):

Arlequim, o empregado trapalhão, ágil e malandro, capaz de colocar o patrão ou a si em situações confusas, que desencadeavam a comicidade. No quadro de personagens, merecem ainda destaque Briguela, um empregado correcto e fiel, mas cínico e astuto, e rival de Arlequim, Pantaleone ou Pantaleão, um velho fidalgo, avarento e eternamente enganado. Papel relevante era ainda o do Capitano (capitão), um covarde que contava as suas proezas de amor e em batalhas, mas que acabava sempre por ser desmentido. ${ }^{5}$

Como podemos notar, cada personagem carrega consigo traços característicos, reconhecidos pelo público, e simbolicamente representados na máscara usada pelo ator ao representá-la.

Em suma, a idéia por trás dessa aproximação das narrativas orais com a expressão teatral da Commedia dell'Arte poderia ser posta nas palavras de Fo ao descrever esse tipo de teatro: "a Commedia dell'Arte se baseia na combinação de diálogo e ação, monólogo falado e gesto executado" (FO, 1998, p. 23); exatamente como percebo a realização dos contos tradicionais/orais.

Em seu livro $O$ teatro épico, Anatol Rosenfeld fala de maneira interessante sobre a natureza dos textos dramáticos. Segundo ele, "o paradoxo da literatura dramática é que ela não se contenta em ser literatura, já que, sendo 'incompleta', exige a complementação cênica” (ROSENFELD, 1965, p. 25). É justamente esse o paradoxo no qual se encontram as narrativas tradicionais/orais cristalizadas pela escrita. Muito de sua significação está nos bastidores da palavra. Para entendê-las completamente é necessário descerrar as cortinas, não se contentar só com o texto, mas buscar o gesto, a voz, a realização cênica, em suma: a performance. Quanto à dimensão desse termo, me ancoro nas reflexões feitas por Paul Zumthor em seu livro Leitura, recepção e performance.

A primeira idéia de Zumthor que quero aqui vincular à manifestação das narrativas orais é sua visão, lúcida e poética, acerca do fenômeno literário, chamado por ele, amplamente, de fenômeno poético (englobando nesse termo o que a cultura ocidental letrada convencionou chamar de Literatura). Segundo Zumthor, o que caracteriza a poesia é sua manifestação enquanto linguagem ritualizada, que leva à "convergência profunda entre performance e poesia, na medida em que ambas aspiram à qualidade de rito" (ZUMTHOR, 2000, p. 53). Temos aqui exposta uma certa ancestralidade que ainda marca o fenômeno literário. Com efeito, não só a arte de contar histórias, mas, em certa medida, muitas outras artes (música, dança, teatro, pintura) engendram-se nos rituais religiosos mais antigos. A inovação da idéia de Zumthor é que ele define a poesia ${ }^{6}$ (literatura) por esse caráter ancestral, ou seja, para ele ainda há algo de ritual na literatura, mesmo que latente, e que transparece na sua manifestação, caracterizando o fenômeno poético. O que transparece é a performance. Mas o que seria esse caráter ritual da poesia e como ele se manifesta na sua forma ritual? E como podemos ter acesso a ele? O próprio Zumthor nos dá um exemplo desse fenômeno poético e sua manifestação performática, extraído das suas memórias de infância. Apesar de extenso, permito-me citá-lo, dadas a riqueza e a pertinência das descrições:

Entro nessa matéria pela evocação de uma lembrança que não apenas me é cara mas que está profundamente inscrita em mim, e permaneceu subjacente a tudo que eu ensinei nos últimos quinze anos. Isto tem a ver com minha infância parisiense, as idas e vindas entre o subúrbio em que habitavam meus pais e o colégio do nono distrito, onde, no começo dos anos 30 , eu fazia meus estudos secundários. Nessa época, as ruas de Paris se animavam por numerosos cantores de rua. Eu adorava ouvi-los: tinha meus cantos preferidos, como a rua do Faubourg Montmartre, a rua Sant-Denis, meu bairro de estudante pobre. Ora, o que percebíamos dessas canções? Éramos quinze ou vinte troca-pernas em trupe ao redor de um cantor. Ouvia-se uma ária, melodia muito simples, para que na última copla pudéssemos retomá-la em coro. Havia um texto, em geral muito fácil, que se podia comprar por alguns trocados, impresso grosseiramente em folhas volantes. Além disso, havia o jogo. O que nos havia atraído era o espetáculo. Um espetáculo que me retinha, apesar da hora de meu trem que avançava e me fazia correr em seguida até a Estação do Norte.

Havia o homem, o camelô, sua parlapatice, porque ele vendia as canções, apregoava e passava o chapéu; as folhas-volantes em bagunça num guarda-chuva emborcado na beira da calçada. Havia o grupo, o riso das meninas, sobretudo no fim da tarde, na hora em que as vendedoras saíam de suas lojas, a rua em volta, os barulhos do mundo e, por cima, o céu de Paris que, no começo do inverno, sob as nuvens de neve, se torna violeta. Mais ou menos tudo isso fazia parte da canção.

\footnotetext{
Na Commedia dell'Arte ocorre o uso de máscaras por parte dos atores, cada qual representando uma personagem distinta. Disponível on-line em: <http://www.fcsh.unl.pt/edtl/index.htm>. Acesso em: 15 jan. 2007.

Dada a filiação explícita à teoria de Zumthor, esteja o leitor atento para o uso que farei, de agora em diante, do termo poético como sendo o literário (Literatura), deixando claro que, segundo a concepção do autor, o literário pertence ao poético, é uma dentre suas várias manifestações históricas.
} 
Era a canção. Ocorreu-me comprar o texto. Lê-lo não ressuscitava nada. Aconteceu-me cantar de memória a melodia. A ilusão era um pouco mais forte mas não bastava, verdadeiramente. O que eu tinha então percebido, sem ter possibilidade intelectual de analisar era, no sentido pleno da palavra, uma "forma": não fixa nem estável, uma forma-força, um dinamismo formalizado. (ZUMTHOR, 2000, p. 32-33).

Essa forma-força, esse dinamismo do qual fala Zumthor é a performance, realizando-se em uma de sua características: a de ser um fenômeno, a de residir na efemeridade de um momento distinto. Assim, a performance, como bem define o próprio Zumthor (2000, p. 38), nos coloca frente à "“forma', improvável", sendo que lingüisticamente se situa "entre o sufixo designando uma ação em curso, mas que jamais será dada por acabada, e o prefixo globalizante, que remete a uma totalidade inacessível, se não inexistente". Se passarmos a analisar a experiência vivenciada e acima relatada por Zumthor, podemos vislumbrar a complexidade que envolve a realização de um fenômeno poético em performance. Fôssemos construir uma equação com todas as variáveis descritas (o espaço, o tempo, o clima, o cantor, os ouvintes, etc) mais as implícitas (o espaço sócio-histórico, as expressões, os gestos, o tom de voz, etc), que afetaram a realização da performance vivenciada, chegaríamos à óbvia conclusão da impossibilidade de repetição dessa performace tal qual "experienciada" pelo autor. Sendo assim, a única maneira de termos acesso à performance é através da vivência. É-nos impossível apreender o fenômeno performático. Não podemos nem mesmo analisá-lo em suas partes, escandi-lo de maneira racional e discursiva. A performance não pressupõe regras formais, maneiras de ser pré-determinadas, ela é a própria forma do poético, ela é a totalidade, é nela e através dela que se dá a gênese, o desenvolvimento, o ápice e a "morte" da realização do fenômeno poético. Podemos, desse modo, apropriarmo-nos, no máximo, de uma parte integrante da totalidade do fenômeno performático (assim como o fez Zumthor ao comprar o folheto do seu cantor de rua ou ao cantarolar a melodia da canção - ou como fazem, para lembrarmos o objeto aqui em questão, aqueles que coletam as narrativas na oralidade e as cristalizam pela escrita). Porém, torna-se um abuso querermos analisar, classificar e impor juízo de valor a esse fenômeno, entrando em contato com uma parte, somente. Não quero com isso propor a impossibilidade do discurso sobre o poético, apenas chamar a atenção para a complexidade ignorada e implícita em certos discursos poéticos, a exemplo das narrativas tradicionais/orais, tema deste ensaio, que se realizam de maneira plena somente em contextos performáticos, contexto o qual é muitas vezes ignorado ou posto em segundo plano, ao falar-se dessas manifestações. A performance, o acesso a ela através da vivência, o caráter ritualístico desta, que necessariamente pressupõe mediações do corpo e de contextos coletivos, tudo deve ser pensado e estar presente nas análises do fenômeno poético das narrativas tradicionais/orais, dado que significam.

Apesar de seu caráter volátil, podemos inferir certos traços marcantes da performance. Zumthor (2000, p. 36-37) nos aponta quatro: "Performance é reconhecimento"; "Performance é reiterabilidade"; "A performance se situa num contexto cultural e situacional"; e "A performance e o conhecimento daquilo que se transmite estão ligados, naquilo que a natureza da performance afeta o que é conhecimento". Tentemos ligar esses traços, retomando idéias já expostas.

A localização da performance num contexto cultural impõe a ela a questão já mencionada da vinculação de um universo de temas e motivos da tradição na qual está inserida. Esses elementos tradicionais afloram no contexto situacional de realização da performance, no narrar de uma história por parte de um contador ou na apresentação de uma peça da Commedia dell'Arte, por exemplo. Isso implica o caráter de re-conhecimento da performance. O público espectador do nosso contador de histórias ou dos nossos atores (re)conhece os temas, motivos e formas que pertence ao seu universo cultural. Porém, esse conhecimento é modificado a cada realização performática, dada a impossibilidade de solidificação de uma única performance, posto seu caráter fenomênico. Assim, a performance se amalgama ao conhecimento tradicional que vincula, mas também o tenciona, rumo a modificações, pois cada indivíduo quando no ato de performance elege alguns elementos em detrimento de outros da ordem do seu contexto espaço-temporal, sócio-cultural e acrescenta elementos surgidos da sua imaginação criadora. Isso se liga ao caráter reiterável da performance. Apesar de vincular elementos tradicionais conhecidos, ela nunca é a mesma, ela nunca cansa os indivíduos que a assistem, pois cada realização performática é única em seus elementos situacionais e individuais constituintes.

Retornando a analogia inicial deste ensaio, entre as narrativas tradicionais/orais e a peça teatral descrita nas primeiras linhas, retomo a constatação da centralidade do caráter performático nelas presente. Espero tê-lo demonstrado com as comparações entre contos tradicionais/orais e expressões teatrais no que tange às limitações do textual. Para além disso, espero ter demonstrado a necessidade de irmos aos bastidores da palavra e de lá trazermos à tona o fenômeno performático, sem o qual ambas as expressões poéticas tornam-se desfiguradas. 
BIBLIOGRAFIA

ANDRADE, Sandra. Commedia dell'Arte. In: E-Dicionário de Termos Literários. Disponível on-line em: $<$ http://www.fcsh.unl.pt/edtl/index.htm>. Acesso em: 15 jan. 2007.

SCHOLLES, R.; KELLOGG, R. A natureza da narrativa. São Paulo: McGrawHill, 1977.

FO, Dario. Manual mínimo do ator. São Paulo: Senac, 1998.

GOMES, Lindolfo. Contos Populares Brasileiros. São Paulo: Melhoramentos, 1918.

HEGEL, Georg Wilhelm Friedrich. Estética. Lisboa: Guimarães Editores, 1965.

ROSENFELD, Anatol. O teatro épico. São Paulo: Ed. São Paulo, 1965.

ZUMTHOR, Paul. Performance, recepção, leitura. São Paulo: EDUC, 2000. 